\title{
A REVOLTA DA VACINA E SEUS IMPACTOS
}

\author{
THE VACCINE REVOLT AND ITS IMPACTS
}

Raniery Augusto dos Santos Beserra Nogueira ${ }^{1}$, Rodrigo José Fernandes de Barros ${ }^{2}$, Jamile Rodrigues Cosme de Holanda ${ }^{2}$, Débora Benício de Melo Monteiro ${ }^{2}$, Luma Ellen Freitas Morais ${ }^{1}$, Julian de Assis Almeida ${ }^{1}$, Antônio de Araújo Tavares Netto ${ }^{1}$, João Victor de Oliveira Tavares Saraiva ${ }^{1}$

${ }^{1}$ Acadêmicos da Faculdade Nova Esperança de Mossoró - FACENE/RN

${ }^{2}$ Professor da Faculdade Nova Esperança de Mossoró - FACENE/RN

Info

Recebido: 07/2020

Publicado: $11 / 2021$

DOI: $10.37951 / 2358-260 X .2021 \mathrm{v} 8 \mathrm{i} 2.5914$

ISSN: 2358-260X

Palavras-Chave

Prevenção da saúde; Atenção primária a

saúde; Vacinação.

Keywords:

Health prevention; Primary health care; vaccination.

\section{Resumo}

Com o aumento da transmissão de varíola e febre amarela, a população carioca foi acometida com vasto número de mortes e se viu grande proporção de contágio por essas doenças. Junto a disseminação dessas doenças no Rio de Janeiro estava havendo a destruição dos casebres e cortiços, no centro e o desalojamento da comunidade pobre, somando-se às tensões provocadas pelo desalojamento, deve ser mencionado também, a implantação da Lei de Vacinação Obrigatória, e a população começou a reagir, provocando a revolta da vacina. tem-se que este trabalho busca realizar uma revisão da literatura, sobre a revolta da vacina e seus impactos na população no século XXI. Para tal foi realizado uma busca nos periódicos capes, utilizando os indexadores "revolta da vacina", "reflexos", "impactos" e "revoltas" de forma associada utilizando o operador booleano "AND". Quanto aos filtros utilizados foram o arquivo estar disponível na integra de forma online e escrito na língua portuguesa. Um dos principais planos de Rodrigues Alves, então presidente da República, era atacar os demônios que assolavam toda a capital, nomeadamente de febre amarela, varíola, etc. A modernização do porto e a reconstrução da cidade faziam parte do projeto. Alves teve a grande responsabilidade de manter a limpeza da cidade e prevenir muitas doenças infecciosas, foram Pereira Passos e o médico Osvaldo Cruz são nomeados para a execução conjunta desta reforma sanitária. Por volta de 1903, diversos planos de campanha liderados por Oswaldo Cruz foram apresentados ao Ministério Público para combater o vetor da febre amarela. 0 serviço de saúde pública deveria prevenir a contaminação dos mosquitos pela doença infecciosa febre amarela, a infecção dos mosquitos infectados e a continuação dos casos esporádicos para garantir a não continuidade da doença durante a epidemia. No caso da varíola, basta vacinar toda a população para controlar a doença.

\section{Abstract}

With the increase in the transmission of smallpox and yellow fever, the population of Rio de Janeiro was affected with a vast number of deaths and a large proportion of contagion by these diseases was seen. Along with the spread of these diseases in Rio de Janeiro, there was the destruction of the shacks and tenements in the center and the displacement of the poor community, adding to the tensions caused by the displacement, it should also be mentioned the implementation of the Mandatory Vaccination Law, and the population began to react, causing the vaccine revolt. this work seeks to carry out a literature review on the vaccine revolt and its impacts on the population in the 21st century. To this end, a search was carried out in capes journals, using the indexers "vaccine revolt", "reflections", "impacts" and "revolts" in an associated way using the Boolean operator "AND". As for the filters used, the file was available in full online and written in Portuguese. One of the main plans of Rodrigues Alves, then president of the Republic, was to attack the demons that plagued the entire capital, namely yellow fever, smallpox, etc. The modernization of the port and the reconstruction of the city were part of the project. Alves had the great responsibility of keeping the city clean and preventing many infectious diseases. Pereira Passos and doctor Osvaldo Cruz were appointed to carry out the joint implementation of this health reform. Around 1903, several campaign plans led by Oswaldo Cruz were presented to the Public Ministry to combat the vector of yellow fever. The public health service should prevent the contamination of mosquitoes by the yellow fever infectious disease, the infection of infected mosquitoes and the continuation of sporadic cases to ensure that the disease does not continue during the epidemic. In the case of smallpox, it is enough to vaccinate the entire population to control the disease. 


\section{INTRODUÇÃO}

O cenário carioca ao final do século XIX teve em sua composição diversos elementos que marcaram o momento da transição econômica, social e política que o país vivenciava. Em 1904, a Revolta da Vacina, ocorrida na cidade do Rio de Janeiro, então capital federal, deu-se num momento decisivo de transformações da sociedade brasileira (FERREIRA, 2015).

No comando de Rodrigues Alves (1902-1906) foi articulado um programa de reurbanização do Rio de Janeiro, objetivando transformar a então capital da República em um cartão postal internacional, para atração de investidores. O período precedente à intervenção direta exercida pelo setor estatal sobre a organização espacial da cidade já trazia fatores determinantes e condicionantes na nova forma de conceber e produzir o espaço: a vinda da corte portuguesa e depois as transições de modelos governamentais, a mudança da mão de obra escrava para a assalariada concomitante à mudança do tipo de atividade econômica - transição para o capitalismo - , ampliação dos meios de transporte e malha viária, saúde pública, grande concentração de cortiços, entre outros (ABREU, 2006; CARVALHO, 1995; CHALHOUB, 2017).

As relações sociais construídas, modificadas e reconstruídas a partir dos anos 70 do século XIX foram circunstâncias importantes para o decorrer da Revolta. O ato da destruição do cortiço mais famoso do Rio de Janeiro, o “Cabeça de Porco" (1893), trouxe uma gama de significados. Encontra-se aí a sistemática perseguição destas moradias e a seus moradores pelas autoridades, iniciada desde 1873, e intensificada nos primeiros anos da República. O incômodo que estas moradias traziam às autoridades na última década do século XIX, tem aspectos diversos: primeiro, quando abrigavam os defensores das causas abolicionistas e republicanas -estes, encastelados, tornavam-se inatingíveis pelas forças estatais (MATTOS, 2005).

Com a destruição dos casebres e cortiços, no centro do Rio de Janeiro, e o desalojamento da comunidade pobre, a população começou a reagir. Somando-se às tensões provocadas pelo desalojamento, deve ser mencionado também, a implantação da Lei de Vacinação Obrigatória com o apoio do médico sanitarista Oswaldo Cruz e o prefeito do Rio, Pereira Passos (CHALHOUB, 2017).

Baseando-se no exposto acima, tem-se que este trabalho busca realizar uma revisão da literatura, sobre a revolta da vacina e seus impactos na população no século XXI. Para tal foi realizado uma busca nos periódicos capes, utilizando os indexadores "revolta da vacina", "reflexos", "impactos" e "revoltas" de forma associada utilizando o operador booleano "AND". Quanto aos filtros utilizados foram o arquivo estar disponível na integra de forma online e escrito na língua portuguesa.

\section{REVISÃO DA LITERATURA}

\section{Causas da revolta}

No Rio de Janeiro, durante os anos de 1903 a 1906, verificou-se um surto populacional advindo da imigração de pessoas estrangeiras para o trabalho nas lavouras de café. Nessa época, percebiam-se estratégias de modernização das zonas urbanas da cidade do Rio de Janeiro, a partir de uma ação conjunta entre o Governo Federal e Municipal, na época representados pelo presidente da república, Francisco de Paula Rodrigues Alves, e pelo prefeito do Rio, Pereira Passos. A convergência das reformas de modernização e o deslocamento de massas populacionais imigradas na cidade foi o contexto para a importação e surto de várias moléstias para a então capital do governo, dentre as quais, a varíola, a febre amarela e outras (FERREIRA, 2015). 
Com o aumento da transmissão de varíola e febre amarela, a população carioca foi acometida com vasto número de mortes e se viu grande proporção de contágio por essas doenças. Em paralelo a esse cenário, as autoridades públicas empreenderam grandes reformas de urbanização, as quais, em escala considerável, provocaram a demolição de casas, cortiços, bem como perseguição da população marginalizada. As consequências desses dois problemas sociais, os surtos epidemiológicos e o surto populacional, ocasionaram índices alarmantes de população sem emprego formal e o avanço da formação de favelas em áreas sensíveis do Rio de Janeiro. É nesse momento que se percebe uma clara insatisfação popular contra o governo de Pereira Passos, pois a expulsão da população pobre das regiões centrais da cidade levou a uma aglomeração em favelas e a formação de bairros periféricos (ABREU, 2006; CARVALHO, 1995; CHALHOUB, 2017).

Diante desse cenário, a varíola se espalhou por todo o estado do Rio de Janeiro. O governo local contratou, à época, um médico especialista no combate a surtos epidêmicos, Oswaldo Cruz, o qual estabeleceu sua ação no combate à proliferação de pragas urbanas. O surto da varíola no que a literatura aponta, teve ainda o lapso de tempo entre os anos 1872 a 1917, e nesse período Oswaldo Cruz determinou que a população carioca deveria ser vacinada de modo compulsório, a partir da faixa populacional com mais de seis meses de idade (HOCHMAN, GILBERTO, 2011).

A sociedade pobre, expulsa do centro do Rio de Janeiro, já descontente com o governo, quando se viu diante dessa obrigação, se opôs de modo violento aos agentes do estado responsáveis pela vacinação oficial. Há registro que agentes de saúde invadiram casas e aplicaram, à força, doses de vacinas nos cidadãos, inclusive com situações de uso de arma de fogo. É nesse contexto que se desenvolveu a chamada
Revolta da Vacina no ano de 1904, com confrontos diretos entre a população pobre, marginalizada, expulsa dos centros urbanos, e as autoridades de saúde pública (HOCHMAN, GILBERTO, 2011)

\section{Fases da revolta da vacina}

Como fator consequente das diversas causas e motivações sociais já relatadas, iniciou-se em novembro de 1904, na cidade do Rio de Janeiro, um dos maiores movimentos populares conhecidos na história, denominado Revolta da Vacina; considerada também como "a mais terrível das revoltas populares da República", de acordo com a imprensa da época. Durante o período de aproximadamente uma semana, 10 a 16 de novembro, a cidade do Rio foi paralisada e tornou-se um verdadeiro local de protestos, revoltas e ataques (PORTO, 2003; RIO DE JANEIRO, 2006; SALGADO, 2018).

Anteriormente à concretização real do motim popular, é válido ressaltar a conjuntura política da época. Tendo em vista o fato de a campanha de vacinação ser um projeto diretamente ligado à presidência da República, e de sua responsabilidade, a oposição política ao governo utilizou-se da situação como meio de se rebelar contra Rodrigues Alves. Esse fator está diretamente associado às disputas ocorridas anteriormente entre o Partido Republicano Federal (PRF) e o Partido Conservador (PC). Dessa maneira, em 5 de novembro do mesmo ano, foi instituída a Liga contra a Vacina Obrigatória, orientada por Vicente de Sousa e alguns positivistas, como Lauro Sodré, de maneira a combater a ação governamental e instigar o povo à revolta (RIO DE JANEIRO, 2006; CASTRO, 2016).

Apesar das ações opositoras contra o projeto estabelecido, a lei que tornava a vacinação obrigatória foi votada e regulamentada no dia 9 de novembro de 1904, difundindo-se a notícia ao ponto de ser destaque 
publicado no jornal 'A Notícia'. Esse acontecimento tornou-se o estopim para a revolta, e, logo no dia seguinte à publicação, cerca de 5 mil pessoas -dentre civis, militares, opositores e sindicalistas- se reuniram na região do Largo de São Francisco de Paula, Rua do Ouvidor, e Praça Tiradentes de forma a protestar contra a medida estabelecida. As autoridades civis são informadas e concentram-se nos locais de protesto de maneira a dispersar o povo e proibir tais reuniões. São tomadas medidas extremas como a prisão dos oradores, o que ocasionou resistência e ataque por parte da população. Então, foi iniciado um combate com reforço policial, fato que duraria o restante da noite gerando um clima de inquietude na cidade (RIO DE JANEIRO, 2006; SEVCENKO, 2010; SALGADO, 2018).

No dia seguinte, mesmo diante da proibição, a Liga contra a Vacina Obrigatória planejou uma reunião popular no Largo de São Francisco, entretanto, mediante à situação, os oradores não compareceram. Ainda assim, os populares iniciaram um discurso improvisado, proferindo ataques ao projeto governamental mantendo todo o público ativo. Nesse momento as autoridades policiais são orientadas a intervir, inicia-se então um confronto da população, que atacava a polícia com pedradas, pedaços de madeira e outros materiais. Diante dessa ação é ordenada uma carga de cavalaria contra a população manifestante, dáse início, assim, ao conflito que ocasionou em diversos feridos, 18 pessoas presas, destruição de partes da cidade e fechamento dos comércios, bancos e repartições (LOPES, 2000; RIO DE JANEIRO, 2006; SEVCENKO, 2010).

Durante os dias 12 e 13 os eventos se repetem, dessa vez nas proximidades da praça Tiradentes e no Centro das Classes Operárias. Lauro Sodré e Barbosa Lima tentavam garantir a liderança do movimento popular, porém sem resultado, pois a população estava inteiramente ligada à busca por respeito, e não meramente a projetos políticos. A partir dessa data, os dias seguintes representaram o ponto alto da rebelião, os protestantes realizaram o ataque inicialmente ao automóvel do chefe de polícia Cardoso Castro, houve tiros, destruição das lâmpadas de iluminação pública, bondes incendiados e extração dos calçamentos de rua. O cenário foi totalmente transformado. Os representantes das forças armadas tentavam a todo custo controlar os focos de revolta, que nesse momento já haviam se espalhado por diversos bairros da cidade; alguns oficiais foram então deslocados de outras cidades de maneira a contornar a situação, sendo divididos em três zonas de policiamento (RIO DE JANEIRO, 2006; SEVCENKO， 2010; CASTRO, 2016).

Por volta do dia 14 de novembro as manifestações se ampliaram, delegacias e hospitais foram invadidos, casas tomadas à força para tornaremse fortalezas e lojas de armas saqueadas. Os guardas civis intervieram e iniciaram um embate no Campo de Marte, que deixou diversos mortos e feridos. Nesse mesmo período a oposição política tentou utilizar do momento e iniciar sua rebelião por meio da Escola Tática de Realengo, entretanto, foram interrompidos pelo comandante Hermes da Fonseca.

A revolta popular prosseguiu por algum tempo, e após diversos combates e movimentos militares, no dia 16 de novembro, foi decretado estado de sítio e revogada a obrigatoriedade da vacina, reduzindo e desarticulando assim os grupos revoltosos. Por volta do dia 20, a rebelião foi oficialmente finalizada, resultando na prisão de 40 mil indivíduos e 460 deportados (RIO DE JANEIRO, 2006; CASTRO, 2016).

\section{Consequências e impactos socioeconômicos}

A cidade do Rio de Janeiro, desde sua fundação, tem uma característica importante, que é suas 
belezas naturais (não obstante, tornou-se a capital federal em 1763), no entanto, no início do século XX, seu contexto social anteriormente citado não era condizente à Belle Époque brasileira. Desde a abolição da escravatura, em 1888, a pobreza foi emergente na capital e suas consequências afearam a Cidade Maravilhosa. No meio de mansões, palacetes e construções extraordinárias, as habitações coletivas como os cortiços- destoavam e chamavam a atenção para a desigualdade vivida, sendo um lembrete, aos governantes, dos problemas urbanos e das desigualdades sociais (CARVALHO, 2016).

Essa situação favorecia a proliferação de graves doenças, fazendo do Rio um foco de epidemias a nível internacional. Diante disso, sabe-se que Pereira Passos, em consonância com Rodrigues Alves, colocou em prática um projeto de modernização urbana, visando à promoção da imagem brasileira e à atração de investimentos para a cidade. Infelizmente, tal medida marginalizou a população pobre, dando início à formação de favelas em morros e terrenos de risco (CASTRO, 2016).

Apesar da desarmonia, a população pobre era responsável pela consolidação do capitalismo na cidade, os trabalhadores ambulantes e seus lucros incertos, seus quartos sujos e seus serviços diários (como limpeza de casarões) aqueciam a economia da capital brasileira. Em decorrência do boom da epidemia, os habitantes passaram a debater calorosamente (chegando a fatalmente) temas urbanos, fazendo crescer a violência. Os higienistas foram pioneiros na discussão das condições de vida no Rio de Janeiro e propuseram intervenções para melhorar a qualidade de vida dos cidadãos. Esses profissionais condenavam as condições precárias existentes como animais mortos nas ruas, lixo sem descarte correto e falta de higiene no sepultamento dos cadáveres (BECHIMOL, 1996).
Um dos principais planos de Rodrigues Alves, então presidente da República, era atacar os demônios que assolavam toda a capital, nomeadamente de febre amarela, varíola, etc. A modernização do porto e a reconstrução da cidade faziam parte do projeto. Alves teve a grande responsabilidade de manter a limpeza da cidade e prevenir muitas doenças infecciosas, foram Pereira Passos e o médico Osvaldo Cruz são nomeados para a execução conjunta desta reforma sanitária. Por volta de 1903, diversos planos de campanha liderados por Oswaldo Cruz foram apresentados ao Ministério Público para combater o vetor da febre amarela. O serviço de saúde pública deveria prevenir a contaminação dos mosquitos pela doença infecciosa febre amarela, a infecção dos mosquitos infectados e a continuação dos casos esporádicos para garantir a não continuidade da doença durante a epidemia. No caso da varíola, basta vacinar toda a população para controlar a doença (FERREIRA, 2015).

No dia 9 de novembro de 1904, com a publicação do plano de regulamentação da vacinação obrigatória, teve início a Revolta, cujos manifestantes já protestaram na manhã do dia seguinte. O enfrentamento entre população e polícia durou seis dias, e o centro do Rio de Janeiro assemelhou-se a um campo de batalha, com envolvimento das Forças Armadas e seu arsenal na tentativa de conter os revoltosos. O uso de bombas e o direcionamento de navios de guerra para os bairros populares, destroçou inúmeras construções da cidade (SEVCENKO, 1999).

Frente às perdas de ambos os lados e o caos que a cidade se tornou, Rodrigues Alves revogou a lei da obrigatoriedade da vacinação. A decisão foi o fator determinante para o término deste conflito, se extinguindo tão rapidamente quanto sua ascensão (SEVCENKO, 1999). Tamanho foi o conflito que, ainda hoje, a Revolta da Vacina é considerada um dos 
maiores conflitos brasileiros do século XX (CHALHOUB, 2017).

Com o fim da revolta, as campanhas de vacinação prosseguiram normalmente, sendo em vão os esforços da população a curto prazo. As atitudes tomadas pelo Governo, mostraram profundo descanso com as necessidades dos menos favorecidos, evidenciando a plutocracia sempre vivida no Brasil. Como se vê, a Revolta da Vacina foi parte de um movimento social muito mais extenso e, a longo prazo, culminou na reformulação da sociedade brasileira, destacando-se a metamorfose urbana da então Capital Federal, o estabelecimento de medidas de saneamento, a nova distribuição espacial de vários grupos sociais, a demolição dos cortiços, a construção das avenidas e a ida da população despejada para os morros (SEVCENKO, 1993).

\section{Os reflexos pós revolta da vacina}

A Revolta da Vacina contra a vacina da varíola teve grandes impactos devido aos reflexos que surgiram tanto na remodelação urbana como no ponto de vista da população e principalmente aos seus direitos como cidadãos e a obrigatoriedade quanto à vacina (MACEDO, 2019).

Os reflexos na remodelação urbana após a vacina decorreram da criação de um projeto durante a gestão do presidente Rodrigues Alves (1902-1906) que foi nomeado com o "Bota-Abaixo", cujo objetivo era desapropriar e demolir os cortiços para a abertura de novos espaços, e também foram tomadas medidas importantes de higienização com o ideal de criar uma cidade destinada a ser o reflexo do Brasil republicano moderno. Enquanto isso, o prefeito Pereira Passos liderou uma série de reformas públicas na área portuária da cidade e outra comissão, liderada pelo engenheiro Paulo de Frontin, comandou obras de aberturas da avenida central (atual Avenida Rio Branco), da Avenida do Cais (atual Avenida Rodrigues Alves) e do Canal do Mangue (MACEDO, 2019).

O responsável pelos projetos para higienizar a cidade, Oswaldo Cruz, teve que lidar com graves problemas como o enfrentamento da febre amarela, a peste bubônica e a varíola. Para combater essas doenças, ele agiu no sentido de exterminar seus vetores que foi o mosquito no caso da febre amarela, e os ratos no caso da peste. Para combater os mosquitos transmissores da febre, foram postos em ação guardas "mata-mosquito" que visitavam as casas em várias regiões da cidade e na maioria dos casos eram acompanhados por soldados da polícia. Ao passo que o combate aos ratos foi relacionado à intensificação da limpeza pública, a lei de vacinação obrigatória foi aprovada para enfrentamento da varíola, já que visava a vacinação em massa da população (CARVALHO, 2005; CASTRO, 2016; CHALHOUB, 2017).

No projeto de vacinação compulsória, estava explícita a obrigatoriedade de comprovação da imunização para se casar, se empregar, viajar, se hospedar e até se matricular em escolas; caso a determinação de vacinação obrigatória não fosse atendida, o cidadão estaria sujeito à multa. Quando essa notícia vazou pela imprensa, a revolta da população foi ainda maior, o que provocou uma série de manifestações com conflitos generalizados por volta de uma semana (ARRETCHE, 2007).

O estopim para a onda de protestos foi a vacinação obrigatória, mas logo a população direcionou sua revolta contra outras camadas do poder como: serviços públicos em geral bem como aos representantes do governo, explicitamente contra as forças repressivas. Após isso, a obrigatoriedade da vacina foi encerrada e a vacinação tornou-se opcional (ARRETCHE, 2007).

Após o período de mais turbulência, a vacinação foi sendo incorporada lentamente no 
cotidiano da sociedade. Assim, houve um declínio rápido no índice de mortalidade causado pela varíola, que no ano de 1906 se tornou praticamente zero na capital. Apesar do sucesso em controlar os índices de morbimortalidade por varíola nas duas décadas iniciais do século XX e do aumento da prevalência de sua forma benigna nos anos 30, houve resultados reversos na população. Diferente de doenças como lepra (atual hanseníase), febre amarela, malária e tuberculose, a varíola não criou uma tradição de pesquisa e desenvolvimento tecnobiológico, não penetrou com relevância em escolas médicas, não organizou uma comunidade de especialistas e não produziu rotinas de notificação, registro e vigilância (HOCHMAN; FONSECA, 1999)

\section{Importância da revolta e a relação com a situação atual}

Diante do exposto, a ideia apresentada por Moutinho et al. (2020) é fortalecida na visão de que a Revolta da Vacina teve apenas seu estopim na vacinação e, na verdade, teve maior cunho político e socioeconômico. De maneira análoga ao contexto dessa população, os brasileiros atuais vivemos em profunda instabilidade social, política e econômica, afetando o funcionamento do país, sobretudo no que diz respeito ao enfrentamento da pandemia da Covid-19, causada pelo SARS-CoV-2.

Se for feita uma análise retrospectiva, a situação do país permanece a mesma que a citada por Batista (2015), sempre com uma parcela populacional tendo seus direitos ameaçados em detrimento do "desenvolvimento da nação" -ficando, esse desrespeito, mais evidente de tempos em tempos. Ainda que a Revolta não tenha surtido os efeitos almejados pela população, o movimento mostrou que a suspensão de seus direitos não é algo a ser imposto e simplesmente aceitado. Além disso, a rebelião favoreceu o fortalecimento das defesas governamentais, tendo influência também no viés da segurança, já que foram pensadas estratégias e táticas para possíveis futuros levantes.

O povo fluminense fez história ao rebelar-se contra as injustiças que estavam sofrendo e tornou-se ponto de discussão na educação em ciências humanas e ciências da saúde. Hoje, os revoltosos são exemplos de que a luta pelos direitos de todos é de extrema importância, além de serem citados em amplas questões sobre imunização e história do movimento em saúde brasileiro (BATISTA, 2015).

Sendo um dos ideais propagados pelos revoltosos que ecoa até hoje no Brasil é base do movimento anti-vacina, o qual vem ascendendo nos últimos anos, graças à desinformação e ao desfavor humanitário que é a propagação de notícias falsas. Ao passo que no início do século XX se defendiam questões de pudor perante a vacinação, no século XXI prioriza-se a autonomia e a vontade populacionais em detrimento da imunização. Infelizmente, o que a maior parcela dos contrários às vacinas não sabe ou escolhe ignorar é que o ato de "tomar uma vacina" é assinar um pacto coletivo para que sejam alcançadas melhorias na saúde de todos; vai muito além de uma proteção individual, partindo para a garantia de proteção a todas as classes sociais, desde o cidadão mais ao menos favorecido (GUGEL et al., 2021).

Esse crescimento na adesão ao movimento anti-vacina mostra-se uma afronta direta ao Programa Nacional de Imunização (PNI) e um prejuízo ao Sistema Único de Saúde (SUS), porque cada abstenção na vacinação repercute em obstáculos na garantia de proteção e promoção da saúde de todos. Ademais, cada indivíduo que se priva da imunização passiva está, também, expondo toda a população ao seu redor ao risco de contrair doenças infecciosas que poderiam estar controladas (GUGEL et al., 2021). Um exemplo 
disso, é a perda do certificado de erradicação em sarampo: Em 2016 o Brasil teve erradicação do sarampo reconhecida, no entanto, por uma queda da cobertura vacinal, o vírus voltou a circular de maneira endêmica, e o certificado foi perdido no final de 2018. Portanto, fica evidente que não se pode medir a influência da Revolta da Vacina, pois ela reverbera em amplos aspectos sociais, seja de maneira intensa ou não.

\section{CONCLUSÃO}

$\mathrm{Na}$ atualidade, após o crescimento de uma polarização política nas últimas décadas, o País se vê em um fanatismo ideológico que só o prejudica a cada dia mais. Assim como os brasileiros de 1904, a massa populacional traz as questões socioeconômicas e, principalmente, políticas como justificativa à maneira de se portar no âmbito da saúde; continua usando de sua autonomia e do poder que lhe é emanado para protestar, seja contra ou a favor das medidas governamentais, em meio a um problema mundial de saúde; segue fechada, muitas vezes, ao contexto geral do que se está sendo vivido, não tendo a percepção necessária do número de enfermos, do número de óbitos e do perigo eminente de colapsar toda uma nação.

Diante de tal cenário, a sociedade do século XXI, já nota e aceita que a vacinação é importante no combate de muitas doenças que já são conhecidas para evitar novas epidemias ou pandemias que possam afetar a sociedade, isso devido aos conhecimentos adquiridos ao longo dos anos.

\section{REFERÊNCIAS}

ABREU, Maurício de Almeida. Evolução Urbana do Rio de Janeiro. 4. ed. Rio de Janeiro: Instituto Municipal de Urbanismo Pereira Passos, 2006. 137 p.
AVENTURAS NA HISTÓRIA. São Paulo: Grupo Perfil, 17 fev. 2021. Mensal. Disponível em: $<$ https://aventurasnahistoria.uol.com.br/notici as/almanaque/reurbanizacao-medo-e-caos-6fatos-para-entender-o-que-foi-a-revolta-davacina.phtml>. Acesso em: 18 Maio 2021.

BATISTA, Alexsandro Marchesini. REVOLTA DA VACINA. 2015. 14 f. TCC (Graduação) - Curso de História, Universidade Estácio de Sá, Vila Velha, 2015.

BENCHIMOL, JL. Pasteur, a Saúde Pública e a Pesquisa Biomédica no Brasil. In: Lima, NT, Marchand, MH. (orgs.). Louis Pasteur \& Oswaldo Cruz. Rio de Janeiro: Editora, 1996.

BRASIL. GILBERTO HOCHMAN. (org.). Vacinação, varíola e uma cultura da imunização no Brasil. Ciência \& Saúde Coletiva, Rio de Janeiro, v. 16, n. 2, p. 375-386, fev. 2011. FapUNIFESP (SciELO). http://dx.doi.org/10.1590/s1413-

81232011000200002. Disponível em: <https://www.scielo.br/scielo.php?script $=$ sci_ arttext\&pid $=$ S1413-81232011000200002>. Acesso em: 17 Maio 2021.

BRASIL. Lei 9.610, de 19 de fevereiro de 1998. Altera, atualiza e consolida a legislação sobre direitos autorais e dá outras providências. Diário Oficial da União, Brasília, 20 fev. 1998.

BRASIL. Ministério da Saúde. Secretaria-Executiva. Subsecretaria de Assuntos Administrativos. Organização Administrativa do Ministério da Saúde: resumos executivos dos atos normativos. Ministério da Saúde, SecretariaExecutiva, Subsecretaria de Assuntos Administrativos. Brasília. 2006.

CARVALHO, J. Bestializados; CASTRO, S. República; CHALHOUB, S. Cidade; Fiocruz. A trajetória de Oswaldo Cruz e sua luta como médico sanitarista no século $19 . \quad$ Disponível em: < http://www.fiocruz.br/cgi/cgilua.exe/sys/sta rt.htm? infoid=1084\&sid =194> $<$ https://portal.fiocruz.br/noticia/revolta-davacina $>$. Acesso em: 17 Maio 2021.

CARVALHO, José Murilo de. A formação das almas: o imaginário republicano no Brasil. São Paulo: Companhia das Letras, 1990. 
CARVALHO, José Murilo. Os Bestializados. O Rio de Janeiro e a República que não foi. São Paulo: Companhia das Letras, 2005.

CARVALHO, Lia de Aquino; ROCHA, Oswaldo Porto. A era das demolições: habitações populares. Rio de Janeiro: Secretaria Municipal de Cultura, 1996. 189 p.

CASTRO, Juliana Gagliardi/Celso (org.). Revolta da Vacina. 2016. Fundação Getulio Vargas - Atlas Histórico do Brasil. Disponível em: https://atlas.fgv.br/verbetes/revolta-da-vacina. Acesso em: 16 Maio 2021.

CHALHOUB, Sidney. Cidade febril: cortiços e epidemias na Corte imperial. 2 ed. São Paulo: Companhia das Letras, 2017. 278 p.

FERREIRA, Ingrid Gomes. AS REFORMAS URBANAS NA CIDADE DO RIO DE JANEIRO NO INÍCIO DO SÉCULO XX E XXI: O porto em questão. 2. ed. Rio de Janeiro: Anais do II Encontro Internacional: Histórias e Parceria, 2015. 16 p. Disponível em: $<$ http://www.conhecer.org.br/download/cp/

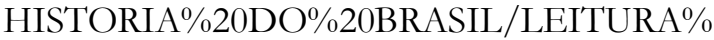
20ANEXA $\% 20$ MODULO $\% 20 \mathrm{III} \% 20$ \%20a.pdf.>. Acesso em: 10 Maio 2021.

GUGEL, Sandrieli et al. PERCEPÇÕES ACERCA DA IMPORTÂNCIA DA VACINAÇ̃̃O E DA RECUSA VACINAL: uma revisão bibliográfica / perceptions about the importance of vaccination and vacinal refusal. Brazilian Journal Of Development, [S.L.], v. 7, n. 3, p. 22710-22722, mar. 2021. DOI: $10.34117 / \mathrm{bjdv} 7 \mathrm{n} 3-135$.

HOCHMAN, Gilberto; FONSECA, Cristina Maria Oliveira. O que há de novo? Políticas de saúde pública e previdência, 1937-45. In: PANDOLFI, Dulce Chaves. Repensando o Estado Novo. [S.L.]: Fgv, 1999. Cap. 5. p. 73-93.

LOPES, MB. O Rio em movimento: quadros médicos em história 1890-1920 [online]. Rio de Janeiro: Editora FIOCRUZ, 2000. 136 p. ISBN: 8585676-60-4.

MACEDO, Márcia (org.). Revolta da vacina: manifestação contra a campanha da vacinação obrigatória. Desconhecido: Educa+ Brasil, 2019. Disponível em: $<$ https://www.educamaisbrasil.com.br/enem/ historia/revolta-da-vacina>. Acesso em: 16 Maio 2021.

MATTOS, Revelino Leonardo Pires de. Revolta da Vacina (1904): Varíola e Vacinação. Juiz de Fora: Anais do I Colóquio do Lahes, 2005. 10 p. Disponível em: <http://www.conhecer.org.br/download/cp/ HISTORIA $\% 20 D O \% 20 B R A S I L / L E I T U R A \%$ 20ANEXA $\% 20$ MODULO $\% 20111 \% 20$ \%20a.pdf.>. Acesso em: 10 Maio 2021.

MOUTINHO, Flavio Fernando Batista et al. CONFLITOS DA SOCIEDADE BRASILEIRA COM AS NORMAS SANITÁRIAS: um paralelo entre a revolta da vacina e a pandemia de covid-19. Hygeia Revista Brasileira de Geografia Médica e da Saúde, [S.L.], p. 60-71, 17 jun. 2020.

PORTO, Mayla Yara. Uma revolta popular contra a vacinação. Cienc. Culto., São Paulo, v. 55, n. 1, pág. 53-54, janeiro de 2003. Disponível em $<$ http://cienciaecultura.bvs.br/scielo.php?scrip $\mathrm{t}=$ sci_arttext $\&$ pid $=\mathrm{S} 000967252003000100032$ $\& \operatorname{lng}=$ en $\backslash \mathrm{nrm}=\mathrm{iso}>$. Acesso em: 14 Maio de 2021.

RIO DE JANEIRO (cidade). Secretaria Especial de Comunicação Social. 1904 - Revolta da Vacina. A maior batalha do Rio / Prefeitura da Cidade do Rio de Janeiro. - A Secretaria, 2006. 120 p.: il. -- (Cadernos da Comunicação. Série Memória). Disponível em: $<\underline{\text { http://www.rio.ri.gov.br/dlstatic/10112/420 }}$ 4434/4101424/memoria16.pdf > Acesso em: 14 Maio 2021.

SALGADO, Aline Silva. A Revolta contra a vacina: a vulgarização científica na grande imprensa no ano de 1904. 2018. 128 f. Dissertação (Mestrado) - Curso de Divulgação da Ciência, Tecnologia e Saúde, Fundação Oswaldo Cruz, Rio de Janeiro, $2018 . \quad$ Disponível em: $<$ http://ppgdc.coc.fiocruz.br/images/dissertac oes/dissertacao_aline_salgado.pdf.>. Acesso em: 16 Maio 2021.

SEVCENKO, Nicolau. A Revolta da Vacina. Rio de Janeiro: Cosac Naify, 2010. 144 p. Disponível em:

$<$ https://portalconservador.com/livros/Nicola u-Sevcenko-A-Revolta-da-Vacina.pdf.> Acesso em: 16 Maio 2021. 
SEVCENKO, Nicolau (org.). História da vida privada no Brasil República: da belle époque à era do rádio. 3. ed. [S.L.]: Companhia de Letras, 1999.

SEVCENKO, Nicolau. A Revolta da Vacina. Porto Alegre: Scipione,1999.

\section{VACINAÇÃO, VARÍOLA E UMA CULTURA}

DA IMUNIZAÇÃO NO BRASIL. Rio de

Janeiro: Ciência \& Saúde Coletiva, v. 6, n. 1, 2 mar. 2011. Bimestral. Disponível em:

https://www.scielo.br/scielo.php?script=sci_ar ttext\&pid=S1413-

$81232011000200002 \& \operatorname{lng}=$ pt\&tlng $=$ pt. Acesso em: 14 Maio 2021. 